\title{
Strategy of the regional development and analysis of poverty and the national labor market in Russia
}

\author{
Irina Omelchenko ${ }^{1}$, Vladimir Smirnov ${ }^{1,2}$, Marina Danilina ${ }^{1,2,3,{ }^{*}}$, Oleg Dozortzev ${ }^{1}$, and \\ Alexander Vas'kov ${ }^{1}$ \\ ${ }^{1}$ Research Institute VNII of Labor, Ministry of Labor of Russia, Zemlyanoy Val, 34, 105064 \\ Moscow, Russia \\ ${ }^{2}$ Finance University under the Government of the Russian Federation, Leningradskyprosp., 49, \\ 125993 Moscow, Russia \\ ${ }^{3}$ Russian Economic University, Stremyanny per., 36, 117997 Moscow, Russia
}

\begin{abstract}
The strategy of the regional development must include the possible solutions of the poverty problem. On the basis of the statistical and content analysis the authors research the main trends and indicators of poverty in the regions of Russia and the labor market. The authors present the results of the research of activities of regional programs to reduce the proportion of the population with incomes below the subsistence level.Based on the study, the following conclusions can be drawn: working poor is a consequence of the existing economic system of the Russian Federation;the problem of reducing working poverty is long-term; the problem of reducing the poverty level of workers requires an integrated approach that combines economic and social policies.Addressing the problem of the working poor requires the active involvement of public authorities.
\end{abstract}

\section{Introduction}

To date, the level of the working poor has been steadily declining over the past years, reaching a minimum in 2017. Nevertheless, economic sanctions against the Russian Federation and the coronavirus pandemic pose a significant threat to the working population of the Russian Federation. There is a significant risk of an increase in the working poor by the end of $2020[1,2]$.

The working poor in the RF are concentrated in a number of industries. The number of working poor in various industries is inversely proportional to the average monthly nominal gross wages. This demonstrates the impact of wage levels on the number of working poor.

There is no statistical relationship between the poverty level of workers and indicators of the use of working time.

The industries with the highest number of working poor are:

1. textile production;

2. agriculture;

${ }^{*}$ Corresponding author: marinadanilina@yandex.ru 
3. wood processing;

4. production of furniture;

5. the activities of hotels and catering establishments;

6. housing and communal services;

7. budgetary educational institutions;

8. budgetary cultural institutions.

Thus, we can conclude that the largest number of working poor is observed in the public sector, light industry and agriculture.

These indicators can be explained by the low level of added value in these industries, which does not allow raising the level of wages.

The data of the Federal State Statistics Service allow us to consider the level of working poverty in the context of the federal districts of the Russian Federation.

In the Russian Federation, there is a strong differentiation of federal districts in terms of the number of working poor. The smallest number of working poor is observed in the Urals and North-Western districts. The largest number is in the South and North Caucasian districts.

The reason for the observed territorial differentiation is the disproportions in the economic development of the Russian Federation. The maximum and minimum levels of poverty in the constituent entities of the Russian Federation differ by 4-5 times. The reasons for these imbalances and their consequences require additional study $[1,2]$.

Another aspect of territorial differentiation is the aspect of the settlement. The majority of poor citizens live in localities with a population of less than 50 thousand people.

Such settlements, as a rule, have a vivid economic specialization and a narrow labor market. This leads to difficulty in changing the field of activity, makes it difficult to obtain the education and profession that are in demand.

Living in a small settlement also complicates relocation, since the population's income is not enough to move to a permanent place of residence in another settlement or subject of the Russian Federation.

Thus, there are 3 significant aspects to the issue of working poverty:

1. industry;

2. territorial;

3. the aspect of the settlement.

These problems make it difficult to move the population out of the working poor category. In addition, the ability to support oneself only at the level of survival forms a passive, dependent life position among the working poor. Only a small number of working poor increase the value of their human capital, forming competences that are demanded by the labor market ( $21 \%$ of the poor versus $57 \%$ of the "non-poor") $[1,2]$. Thus, the position of the working poor is linked to the established economic system.

The working poor find it very difficult to improve their status. The above problems prevent this from happening.Addressing the problem of the working poor requires the active involvement of public authorities.

\section{Main trends of the labor market in Russia}

Let's analyze the main trends in the labor market in recent years.In eight years, from 2010 to 2018 , the working-age population declined by 6 million. At the same time, the peculiarity of the current situation lies in the fact that despite the continuing tangible decrease in the population of working age, the labor force remained practically stable until the beginning of 2019 , slightly decreasing (within $0.1-0.7$ percent) after 2016. This stability was provided mainly due to the activity of "young pensioners" who remained in the labor market after they reached retirement age [1]. 
According to the results of the Labor Force Survey (LFS Rosstat) in 2018, the economically active population of the Russian Federation aged 15 years and over was 76.2 million people, or $62.8 \%$ of the total population of this age. Compared to 2017 , it decreased by 95 thousand people, or $0.1 \%$ [1].

According to the results of the first half of 2019, compared to the same period in 2018, Rosstat recorded a decrease in the number of labor force by $1.2 \%$, that is, at a slightly faster pace than in previous years, which may indicate the emergence of a trend towards a reduction in the number of labor force in conditions maintaining the old boundaries of working age. A delay in the labor market of a part of citizens who planned to leave work when they reach the previous retirement age, will apparently change this trend, that is, lead to stabilization or some growth in the number of labor force in the medium term.

In recent years, high indicators have remained - the level of participation of the population in the labor force and the level of employment of the population. So, in 2018, the level of participation of the population in the labor force was $68.9 \%$, (within the boundaries of 15-72 years). The peak of this indicator - a record of average annual values for the entire observation period - was observed in $2016-69.5 \%$ [1].

The level of participation of the population in the labor force (taking into account persons over 72 years old) during 2017-2018 remained at the same level - 62.8\% [1].

The situation with the preservation of high indicators of economic activity of the population against the background of a decrease in the number of people of working age is largely explained by changes in the age structure of the country's population in recent years. In the process of a generational change, only for the period from 2012 to 2018 , the cohort of young people (15 years - 24 years) lost $24.5 \%$ or more than 4.7 million people. As a result, their share in the total population decreased quite noticeably (from $17.4 \%$ to $12 \%$ ).

Accordingly, the number and proportion of economically active youth in the labor force decreased. So, according to Rosstat (LFS), in the first half of 2019, the number of economically active youth in the labor force decreased by almost two times (by 4.2 million people), and the share - respectively, from $11.7 \%$ to $6.2 \%$ [1].

As you know, the level of economic activity of young people in connection with their studies, as well as with the birth of children and the need to care for them is traditionally significantly lower than that of people over 30 . Therefore, the decrease in the proportion of young people with low economic activity in the labor force, with a simultaneous absolute and relative increase in the number of people of the most active working age (30-44 years), as well as an increase in the economic activity of people over working age, provided a high level of economic activity of the population as a whole.

The employment rate of the population (within the boundaries of 15-72 years) on average for the period 2016-2018 remained unchanged and amounted to $65.6 \%$ at the end of 2018 . Only in the first half of 2019, compared to the same period in 2018, the employment rate decreased by one percent, but it is too early to speak of a downward trend. It should be noted that the inclusion in the Labor Force Survey (LFS) of persons over 72 years old (since 2017) was most noticeably reflected in the indicator-indicator "employment rate". The value of the new indicator, calculated for the entire population over 15 years old, is noticeably lower in 2017 and 2018. it was, respectively, 59.5\% and 59.8\% [1].

In 2018 , the situation with employment in the labor market was slightly better than in 2017, according to sample surveys (LFS), the number of people employed in the economy during 2018 increased from 72.3 to 72.5 million people (by $0,2 \%$ ). At the same time, $45.0 \%$ of the total number of employed were concentrated in large and medium-sized enterprises and organizations.

According to Rosstat surveys, the number of unemployed, calculated according to the ILO methodology, slightly decreased in 2018 compared to the previous year and amounted 
to 3.7 million people. The overall unemployment rate in 2018 was $4.8 \%$ of the economically active population [1].

The number of unemployed citizens in the registered labor market who are registered with the employment service also decreased - from 0.76 million people at the end of December 2017 to 0.69 million people in the same period in 2019 [2].

According to the Rosstat survey for 2018, of the total number of unemployed, calculated according to the ILO methodology, 27.3\% (1 million people) had no work experience. Compared to 2017, this indicator increased by 1.3 percentage points. Among the unemployed with work experience, more than a third (37\%) are persons who quit their jobs of their own accord and $21.2 \%$ are persons who left their last job due to staff cuts. Compared to 2017, the share of the unemployed who left their jobs due to staff cuts decreased by 0.8 percentage points [1].

The indicators characterizing the length of stay in unemployment improved slightly in 2018 compared to the previous year. Thus, the average time spent looking for a job by the unemployed decreased by 0.2 months, amounting to 7.4 months. $28.6 \%$ of the unemployed had one or more years of unemployment (in 2017 - 30.4\%). Long-term unemployment is concentrated mainly in rural areas. Although the share of long-term (more than a year) unemployed among rural residents has decreased over the past year by 3.6 percentage points, it is still extremely high $-33.1 \%$ (2018). For comparison, the share of stagnant unemployment among urban residents is $26.1 \%$ [1].

The age composition of the unemployed in the general labor market is quite young - the average age was 36.1 years in 2018. Youth under 25 years old among the unemployed accounted for $22.4 \%$; persons aged 55 and over - $10.4 \%$. Most of the unemployed $-60 \%$ had a professional education, including higher - more than $20 \%$ [1].

The problem of poverty remains one of the significant problems in 2020. Methods for reducing working poverty are the following.

The working poor are one of the most difficult groups of the poor to work with. This is due to the fact that there are no quick ways to increase income for them. If the unemployed can get a vacancy at the labor exchange, and the disabled can get a social pension, then the working poor are deprived of this opportunity.

Reducing the number of working poor can be achieved by increasing their income. This is possible in two cases:

- advanced training of the employee - this path involves investment in human capital, mastering new skills and retraining;

- an increase in the cost of an employee's labor - this path is associated either with an increase in the level of the minimum wage, or with an acceleration of economic growth in the place of residence of citizens. In case of an increase in the level of the minimum wage, the cost of labor resources will rise, and the citizen has a chance to get out of poverty. However, this can lead to an increase in unemployment, since the price of labor will rise, which will contribute to a decrease in the share of labor in production. Accelerating economic growth implies that the demand for labor will rise and its value will rise. Another way to increase the cost of labor of workers may be limiting grass-roots labor migration, which reduces competition for jobs and increases the wages of the working population.

For the most effective reduction in the number of working poor, it is necessary to apply both activities together. Upgrading workers' skills and boosting economic growth are two main measures to reduce working poverty $[3,4]$.

It should also be noted that facilitating relocation for citizens plays an important role in solving this problem. The development of the real estate market allows citizens to move to economically more promising regions of the country, where wages are higher. This reduces the poverty level of workers. 
Based on the study, the following conclusions can be drawn:

1. working poor - a consequence of the existing economic system of the Russian Federation;

2. the problem of reducing working poverty is long-term;

3. the problem of reducing the poverty level of workers requires an integrated approach that combines economic and social policies.

\section{Activities of regional programs to reduce the poverty in Russia}

Research of activities of regional programs to reduce the proportion of the population with incomes below the subsistence levelshowed the following. In accordance with the developed Methodology, the study of activities of regional programs was carried out in the following positions:

1. assessment of the compliance of activities with the task;

2. assessment of the availability and measurability of the expected results for each of the program activities;

3. assessment of the certainty of the timing of the implementation of each of the program activities;

4. assessment of the conformity of the applied methods and tools to the task at hand;

5. assessment of the completeness of information on the resource provision of program activities.

Much attention is paid to the implementation of active programs to promote employment, the implementation of measures to reduce informal employment and the legalization of "shadow" income. In a number of regions, measures have been developed to stimulate investment activity. Most of the programs reflect the planned work to promote the development of small and medium-sized businesses, support individual entrepreneurs and self-employed $[5,6,7]$.

In order to increase (regulate) the level of wages of workers in the budgetary and nonbudgetary sphere in most regions (Altai Territory, Kirov, Novgorod, Penza, Tyumen, Magadan regions, the Republic of Bashkortostan, etc.), it is planned to index the wages of workers in the budgetary sphere to the inflation rate [1,2].

The monitoring of wage arrears to employees of organizations will be carried out in the Stavropol Territory, Penza and Magadan regions.

In the Republic of Bashkortostan, the Magadan Region and the Stavropol Territory, when registering collective agreements and agreements, conditions will be identified that worsen the position of workers in comparison with labor legislation and other regulatory legal acts containing labor law norms $[1,2]$.

In the Voronezh region, it is planned to carry out targeted work on the implementation of the provisions of the trilateral agreement between the government of the Voronezh region, associations of trade unions and associations of employers by employers in terms of increasing wages to a level not lower than the industry average.

In the Republic of Bashkortostan and in the Stavropol Territory, a hot line will open on the legalization of wages and labor relations.

Active employment promotion programs are envisaged in all regions. Most of them are aimed at helping in finding a job and finding employment for unemployed citizens, promoting the employment of women raising children, persons of the older generation, including creating new places for children under the age of 3 in preschool educational organizations; retraining and advanced training of women during their leave to care for a child under the age of three, as well as women with preschool children who are not in labor relations and who have applied to the employment services;vocational training and additional vocational education of citizens aged 50 and over, as well as persons of pre-retirement age; 
training unemployed citizens who, in accordance with the legislation of the Russian Federation, have been assigned an insurance pension and who seek to resume their labor activity, organization of temporary employment for minors aged 14 to 18 years in their free time, unemployed citizens experiencing difficulties in finding a job, unemployed citizens at the age from 18 to 20 years, with secondary vocational education and looking for work for the first time, for employment of unemployed disabled people, parents raising disabled children, parents with many children. In a number of regions (Irkutsk Region, Stavropol Territory), it is planned to provide subsidies to employers to create jobs for the employment of citizens released from institutions serving sentences of imprisonment, persons convicted on probation.

Much attention to measures to support the implementation of investment projects and the development of industrial enterprises, mainly in the form of subsidizing part of the costs of paying interest on loans, reimbursing the costs of creating engineering and transport infrastructure facilities, property tax benefits, is given in the regional programs of Irkutsk, Voronezh, Kirov, Oryol, Penza, Tyumen, Ulyanovsk regions, Altai Territory. These measures are aimed at reducing low-paid employment and creating new highly productive jobs $[1,2]$.

In a number of regions (Voronezh, Rostov regions, Stavropol Territory, the Republic of Bashkortostan), much attention is paid to improving the quality of life of rural residents.

The implementation of projects to support small and medium-sized businesses will be engaged in the Altai and Stavropol Territories, Irkutsk, Kirov, Voronezh, Novgorod, Oryol, Penza, Magadan, Tyumen regions and in the Republic of Bashkortostan. Basically, we are talking about expanding the access of small and medium-sized businesses to procurement of goods, works, services, providing production space and premises on preferential terms (mainly for manufacturing and innovative companies), creating technology parks [1,2].

In most regions, it is planned to implement measures to promote self-employed and individual entrepreneurs, including: teaching the basics of entrepreneurial activity, financial literacy (including schoolchildren, as well as older people); development of self-employment in the field of agriculture and forestry, hunting, fishing and fish farming, consumer services for the population, public catering, retail and retail activities, in the provision of services for the repair and maintenance of vehicles and computer equipment;implementation of projects to promote entrepreneurship, informing residents about measures to support small and medium-sized businesses operating in the region; support for farmers and the development of rural cooperation; implementation of acceleration programs for small and medium-sized businesses; support for the creation of communities of emerging entrepreneurs and the development of the mentoring institution; formation of unified registers of small and medium-sized businesses, self-employed and individual entrepreneurs - recipients of support (Irkutsk, Voronezh, Kirov, Novgorod, Oryol, Penza, Ulyanovsk regions, Altai Territory, Republic of Bashkortostan) [1, 2].

In order to solve the problem of developing a system of social assistance to citizens in need, the activities aimed at an annual increase in insurance pensions (above the inflation rate) have been identified; indexation of social payments and benefits; an increase in the minimum and maximum values of unemployment benefits, monthly payments in connection with the birth (adoption) of the first child through subsidies from the federal budget; monthly payments in case of the birth of a third child or subsequent children before the child reaches the age of 3 years, etc.At the same time, along with the traditional measures of social support in the regions, a number of additional measures are planned, for example, the provision of a monthly cash payment for a child aged 3 to 7 years inclusive, in the amount of $50 \%$ of the subsistence minimum (Irkutsk, Voronezh, Kirov, Orlov, Tyumen, Magadan regions); provision of material assistance to poor families with children under 16 years old (Oryol 
region), provision of free accessible additional education, including using distance technologies, children with disabilities (Novgorod region), etc. [1, 2].

In all regional programs, much attention is paid to measures to develop the social contract system. Among the main directions for the development of the social contract system, inherent in most programs, are assistance in finding a job and finding a job, assisting in vocational training or retraining, assistance in starting their own business, assistance in the development of personal subsidiary farming for low-income citizens within the framework of a social contract [9]. To solve the problem of organizing social adaptation of the poor, most regions plan to provide various social services to low-income families with children, including free visits to museums, sports centers, excursions; carrying out activities aimed at vocational guidance for children and adolescents from poor families, organizing recreation and health improvement for children in difficult life situations.

At the same time, a number of regions have their own specifics. For example, in the Novgorod region they are planning to organize treatment for alcohol dependence; in the Kirov region, they plan to provide state regional social assistance to students belonging to the category of orphans. Meanwhile, the task of social adaptation of poor citizens in the Stavropol Territory is planned to be solved through the construction (reconstruction) of sports facilities owned by the municipalities of the Stavropol Territory, which, in our opinion, requires additional justification. In the program of the Pskov region, measures for the social adaptation of citizens are not provided $[1,2]$.

A number of measures are of an organizational nature, in particular: the creation of a working group on poverty reduction, the development of a system of criteria for assessing and compiling a rating of the activities of local government bodies to increase real incomes of the population and reduce poverty, ensuring the activities of the tripartite commission for the regulation of social and labor relations, and so on. Further. Without reducing the share of the population with incomes below the subsistence level by themselves, other measures create conditions for the effective functioning of measures from the previous blocks [3, 4].

In general, the activities reflected in the program documents correspond to the implementation of the tasks set. At the same time, in each of the regional programs, in one way or another, there are activities whose implementation timeframes do not correspond to the implementation timeframes of the program, there is no information on quantitatively defined indicators / indicators of expected results, information on resource provision is presented with an indication of funding sources, but without calculation target values, or missing.

Thus, without additional elaboration and adjustment of measures for all considered regional programs, there is a risk of failure to achieve the target indicators of the national development goals of the country to ensure sustainable growth in real incomes of citizens and reduce the proportion of the population with incomes below the subsistence level.

\section{Results}

Thus, in 2017 and 2018, the situation on the national labor market was determined by the growth of employment in the economy and the expansion of demand for labor, which generally had a favorable effect on the situation with unemployment. However, the situation on the labor market remains unbalanced. In a number of regions, unemployment rates are significantly higher than the average, while the economy continues to experience a shortage of qualified personnel.

The analysis of the territorial structure of both total and registered unemployment reveals the persistence of its focal character and the existence of significant territorial disparities in local labor markets in most constituent entities of the Russian Federation, especially in rural areas. At the same time, unemployment is predominantly structural in nature. In the face of 
growing demand for labor and an increase in the number of job vacancies, a structural imbalance between supply and demand remains, primarily in terms of professional and qualification characteristics.

As a result of the analysis, it was revealed that the activities presented in the regional programs are mainly related to the position of workers in the labor market, promoting employment, creating conditions for increasing investment activity in the region, supporting entrepreneurship, social payments, expanding the practice of social contracts, social adaptation of the poor citizens.

To solve the problem of increasing the level of income of citizens and exceeding the growth rate of income of citizens, including average wages, over the rate of inflation, most regions provide for the implementation of measures aimed at increasing the income of the working population by indexing the wages of public sector workers, increasing the volume of guarantees employers provided to employees.

Much attention is paid to the implementation of active programs to promote employment, the implementation of measures to reduce informal employment and the legalization of "shadow" income. In a number of regions, measures have been developed to stimulate investment activity. Most of the programs reflect the planned work to promote the development of small and medium-sized businesses, support individual entrepreneurs and self-employed.

\section{Conclusion}

In order to conclude, the modernization of production and the transition to new technologies have led to an increase in employers' requirements for the quality of the workforce. At the same time, the structure of professional training does not always correspond to the demands of the labor market. As a result, in terms of its quantitative characteristics, the supply of labor in the labor market is capable of satisfying the needs of employers, however, the demand of employers increasingly remains unsatisfied, which indicates the problem of a mismatch between demand and supply in terms of qualitative parameters.

Based on the analysis of the dynamics of the number of employed by types of economic activity, it should be noted that a significant increase in the number of employees in the nonproduction sector and a decrease in employment in industrial production affected their share in the structure of employed in the economy. This primarily applies to retail and wholesale trade, where the number of employees in the ten years from 2008 to 2018 increased by 0.9 million people, or $8.1 \%$, and the share of the number of employees increased from $15 \%$ in 2008 to almost $16 \%$ in 2018 .

The problem of poverty remains one of the most significant social problems in Russia. The result of the analysis of the reports of the regional programs which must solve the problem of poverty has shown, that, there was an incomplete correspondence of a part of the reports in the section "Indicators for the implementation of the Regional Program" with the information approved in the framework of regional programs was revealed.

For example, in the report of the Irkutsk region on the implementation of planned measures / control events for the 3rd quarter of 2020, there is no information about the event "Training of specialists of social protection agencies under professional development programs" approved for execution under the regional program. Despite its planned implementation in 2021-2023, in order to ensure comparability, it is recommended to reflect all activities, filling out a note that the activity will be implemented later.We also note that the report of the Irkutsk region on the implementation of planned activities / milestones does not provide quarterly values. This does not allow tracking intra-annual dynamics and creates risks of failure to achieve target indicators. 
Another monitoring problem is the non-simultaneous provision of different program indicators. For example, at the time of writing the report, the responsible executor of the Altai Territory provided a report in the form "Information on the implementation of planned measures / milestones", but did not provide reporting on the forms "Ensuring sustainable growth of real incomes of citizens" and "Reducing the poverty level in RF ". This leads to the impossibility of a full analysis of the implementation of the regional program, which creates risks of failure to achieve the target indicators of the program.

We should also pay attention to the need to update a significant number of regional programs in accordance with methodological recommendations after the examination carried out by the All-Russian Research Institute of Labor.

\section{References}

1. Ministry of Labor and Social Protection of the Russian Federation, official site, https://mintrud.gov.ru/

2. Federal State Statistics Service, official site, https://rosstat.gov.ru/

3. H. Lehmann, Comparative Economic Studies,57(1) (2015)

4. V. Gimpelson, Journal of the New Economic Association, 9(3) (2016)

5. V. Gimpelson, R. Kapeliushnikov, Labor market adjustment: Is Russia different? (2013)

6. J. Earle, K. Sabirianova, Peter Review of Economics and Statistics, 91(4) (2009)

7. V. Gimpelson, R. Kapeliushnikov, A. Sharunina, A. HSE Economic Journal,22(4) (2018)

8. A, Petrin, J. Sivadasan, Review of Economics and Statistics, 95(1) (2013) 